\title{
Vanishing Bile Duct Syndrome in Hodgkin's Disease: case report
}

Department of Internal M edicine and H ematology and B lood Transfusion Center, U niversidade Estadual de Campinas, Campinas, B razil

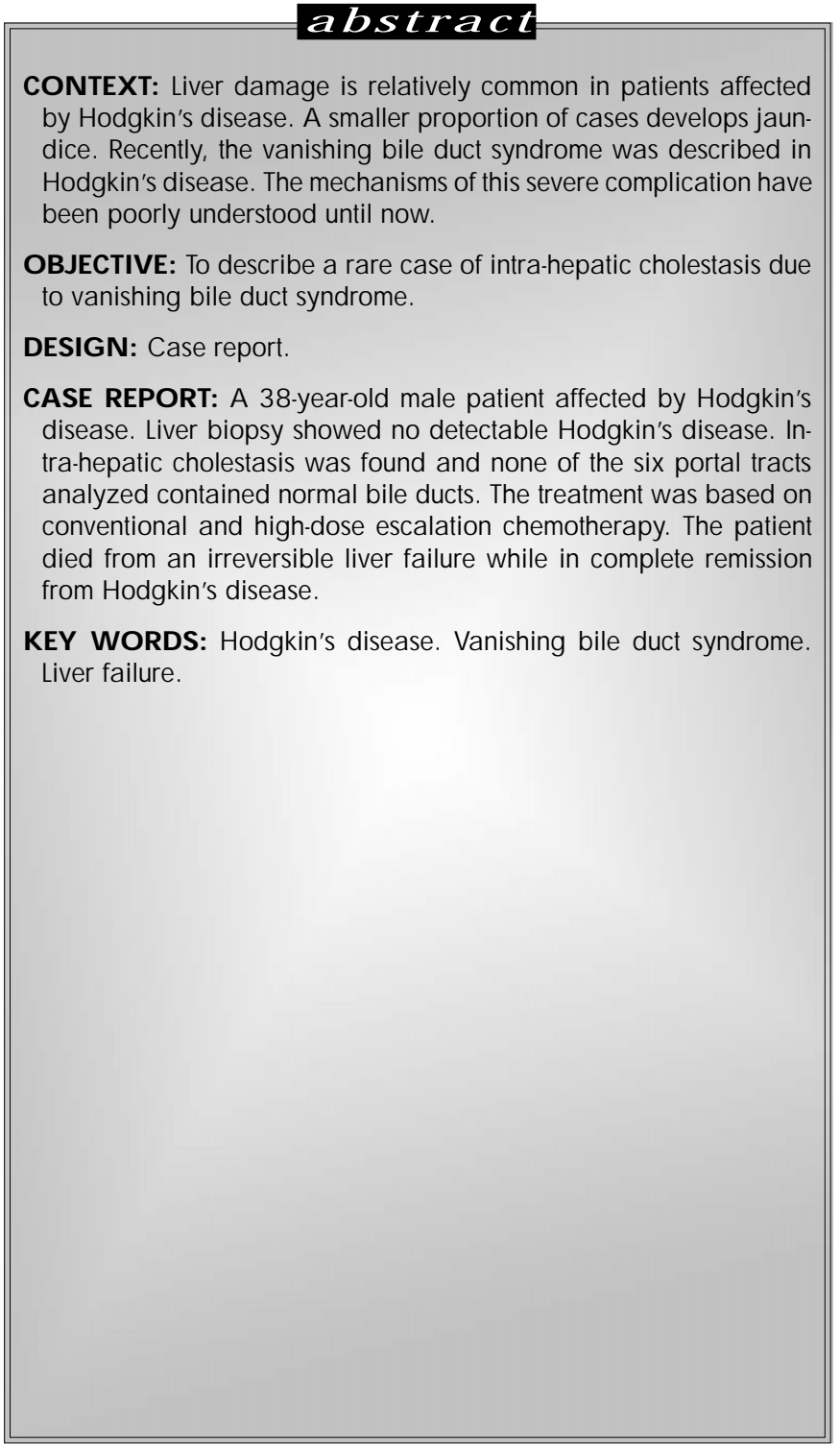

\section{INTRODUCTION}

Liver damage is relatively common in patients affected by Hodgkin's disease. Non-specific inflammation in portal areas is seen in approximately $50 \%$ of liver biopsies, but Reed-Sternberg cells can be demonstrated in about $5 \%$ of them. ${ }^{1}$ However, a smaller proportion of cases develop jaundice. ${ }^{2}$ Other causes of cholestasis in Hodgkin's disease include biliary obstruction (by lymph node enlargement), hemolysis, viral hepatitis and drug toxicity. In the past, many cases that presented no detectable cause of jaundice were called "idiopathic jaundice". Recently, the vanishing bile duct syndrome ${ }^{2,3}$ was described in Hodgkin's disease. The mechanisms of this severe complication have been poorly understood until now. ${ }^{2}$ However, this syndrome has been described in many other diseases such as primary biliary cirrhosis, graft-versus-host-disease or primary sclerosing cholangitis. ${ }^{4,5}$ Vanishing bile duct syndrome is also a major histological finding in rejection after liver transplantation., ${ }^{2,4}$ Advanced vanishing bile duct syndrome is probably a manifestation of irreversible liver damage. ${ }^{2-6}$ We describe a case of Hodgkin's disease associated with vanishing bile duct syndrome.

\section{CASE REPORT}

A 38-year old male was seen at the General Hospital of the State University of Campinas, Brazil, in December 1997. He presented a four-week history of cervical lymphadenopathy, jaundice and pruritus. The lymph node histology showed typical Hodgkin's 
disease, with mixed cellularity (Figure 1). The abdominal computed tomography revealed only hepatomegaly. The X-ray of the thorax and bilateral bone marrow biopsies were normal. $\mathrm{Hb}=15.6 \mathrm{~g} / \mathrm{dl}$; WBC $=7.6 \times 10^{9} / \mathrm{L} ;$ Platelets $392 \times 10^{\circ} / \mathrm{L}$. At the time of admission the biochemical values indicated cholestasis without signs of hepatic failure (Table) Serological tests for hepatitis A, B and C, HIV and cytomegalovirus were negative. Needle biopsy of the liver (Figure 2) showed intra-hepatic cholestasis. Interlobular bile ducts were absent in all of the six portal tracts examined. Involvement by Hodgkin's disease could not be detected. The patient was treated with standard chemotherapy (four cycles of MOPP$\left.A B V^{7}\right)$. Cholestasis progressively increased with signs of hepatic failure (decrease of serum albumin level and elongation of the prothrombin time). During chemotherapy, the patient presented enlargement of a left axillary lymph node. Then, salvage therapy using high dose Cyclophosphamide $7 \mathrm{~g} / \mathrm{m}^{2}$ (HD-CY) followed by Etoposide $2 \mathrm{~g} / \mathrm{m}^{2}$ (VP-16-213) was given to reduce tumor burden and to collect peripheral blood progenitor cell in order to perform autologous bone marrow transplantation. The lymphadenopathy disappeared and there was a short period of stabilization of hepatic function and cholestasis. One month later there was deterioration of the liver function and the patient presented an episode of massive hematemesis with dehydration and acute renal failure. Although a liver transplantation was considered, the patient died due to hepatic failure.

\section{DISCUSSION}

Liver involvement is uncommon in Hodgkin's

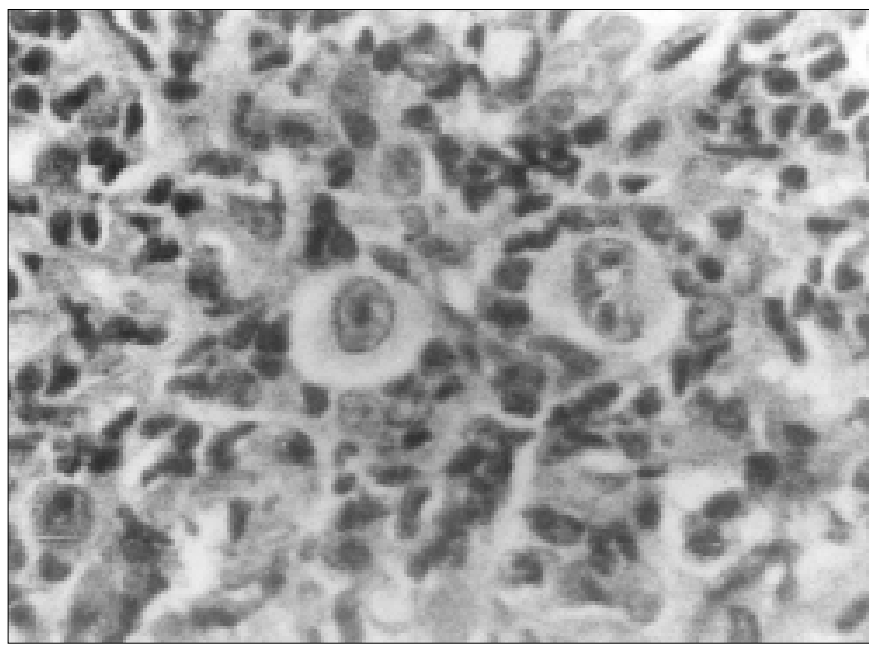

Figure 1. Lymph node biopsy specimen from patient showing typical Hodgkin's Disease, mixed cellularity sub type. disease at diagnosis. Cervantes et $a^{8}{ }^{8}$ found $7.4 \%$ of liver involvement in Hodgkin's disease in 421 cases studied. Infiltration is defined by the presence of Reed Sternberg cells usually accompanied by lymphocytes, histiocytes, eosinophils and plasma cells in the portal tracts. This infiltration of the liver can lead to cholestasis and jaundice. Other causes of jaundice in Hodgkin's disease include extra-hepatic biliary obstruction by enlarged portal lymph nodes, hemolysis, viral hepatitis and drug toxicity. ${ }^{4}$ Recently, the vanishing bile duct syndrome has been described as a rare and severe cause of intra-hepatic cholestasis in Hodgkin's disease. ${ }^{2,3}$

This syndrome consists of the destruction of the biliary apparatus with the disappearance of the small and medium-sized intra-hepatic bile ducts. ${ }^{2,3,5}$ It has been observed in different congenital or acquired diseases such as chronic rejection of liver transplantation, resulting in graft failure in $5 \%$ to $20 \%$ of allograft recipients; graft-versus-host-disease after bone marrow transplantation; primary biliary cirrhosis; primary sclerosing cholangitis; chronic druginduced cholestasis (clindamycin; carbamazepine; trimethoprim-sulphamethoxazole) and histiocytosis $\mathrm{X}$ in children. ${ }^{4-6,9-11}$

Hubscher, et al. ${ }^{2}$ described three cases of Hodgkin's disease that presented reduction of biliary ducts. The three cases died with intractable liver damage. The first case, a 26-year-old man (Hodgkin's disease of the nodular sclerosing type), presented a two-week history of jaundice, fatigue and weight loss. Laboratory studies showed severe cholestasis, although abdominal ultrasound examination showed no evidence of biliary obstruction. He was treated with chemotherapy. He died 24 weeks later

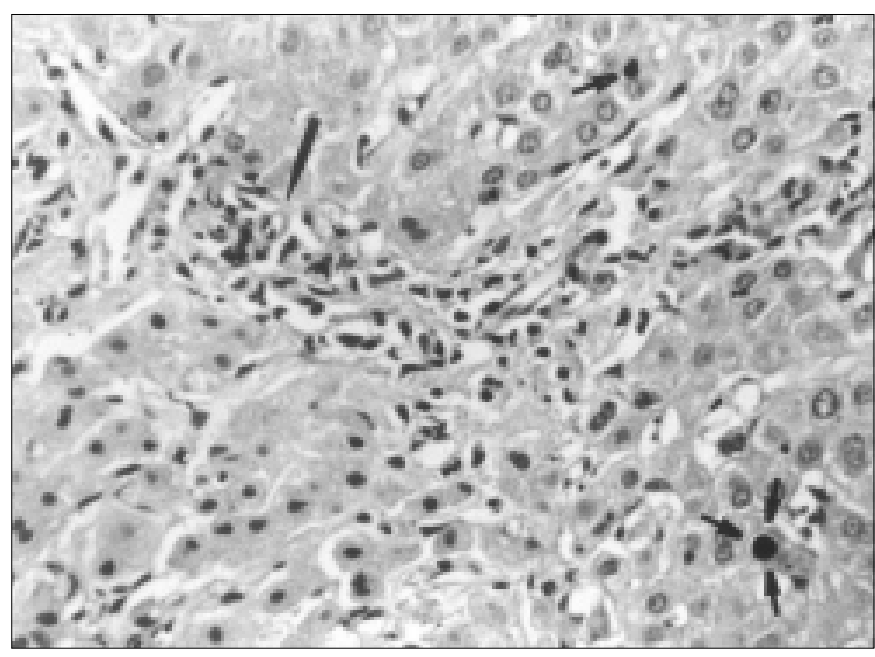

Figure 2. Liver biopsy specimen from the patient. Portal space showing slight mononuclear inflammatory infiltrate. Long arrow shows arteriole without intra-lobular duct. Short arrows show biliary parenchyma plug. 
with hepatic encephalopathy, renal failure, severe diarrhea and neutropenia. The cause of the death was disseminated fungal infection. No residual lymphoma was detected in any of the organs examined at autopsy. The second case, a 44-year-old man, presented a 2-week history of jaundice. The liver biopsy showed intrahepatic cholestasis of unknown pathogenesis. The diagnosis of Hodgkin's disease (lymphocyte predominant type) was made 7 months later. At this time the jaundice got worse and the liver biopsy showed involvement by Hodgkin's disease. He began treatment with radiotherapy and chemotherapy and died three days later. The third case, a 37-year-old woman presented pruritus, weight loss, persistent cough and night sweats. The diagnosis of Hodgkin's disease of the nodular sclerosing type was made by thoracotomy. Ten days after chemotherapy she developed jaundice. The ultrasound examination was normal. Liver function deteriorated and the patient developed renal and respiratory failure and died. At autopsy no residual Iymphoma was detected. In the three cases cholestasis and paucity of bile ducts were noted in the liver biopsies. Only case 2 showed evidence of lymphomatous infiltration. Gottrand et al described a 3.5-year-old child with a three-week history of submaxillary lymphadenopathy. The lymph node biopsy showed a mixed cellularity Hodgkin's disease. On admission she had jaundice without hepatosplenomegaly. The biochemical values were consistent with cholestasis. No infiltration by Hodgkin's disease was found at the liver biopsy. There was a paucity of interlobular bile ducts. Cholestasis progressively increased without any signs of hepatic failure. Chemotherapy and radiotherapy were given. Five months later, the lymphadenopathy had regressed, but cholestasis continued to increase. Liver transplantation was considered, but the patient died with signs of hepatic failure.
In all these four cases described in the literature, as well as in the present one, vanishing bile duct syndrome was detected at diagnosis or at least when Hodgkin's disease showed tumor activity. However, even after a good response to chemotherapy, and complete remission of Hodgkin's disease, vanishing bile duct syndrome progressed. All patients died from irreversible hepatic failure. At autopsy, no evidence of Hodgkin's disease was found.

The pathophysiology of vanishing bile duct syndrome is not well understood. Immunological mechanisms seem to be involved. Hubscher, et al. ${ }^{2}$ suggested that there is a release of toxic cytokines from lymphoma cells in Hodgkin's disease. The destruction of bile ducts in primary biliary cirrhosis, primary sclerosing cholangitis and liver allograft rejection seems to be related to cell-mediated immunological attack by cytotoxic T Iymphocytes of either CD4 or CD8 phenotype. Other investigations have indicated the presence of immunoglobulins in interlobular bile ducts, suggesting the involvement of humoral immune reactions. Hodgkin's disease may be associated with autoimmune manifestations but, even with complete remission of Hodgkin's disease after chemotherapy, vanishing bile duct syndrome is irreversible, probably due to the fact that the affected bile ducts have a low regeneration capacity.

Patients with liver disease as the initial manifestation of Hodgkin's disease have a poor prognosis. In particular, vanishing bile duct syndrome is a progressive and always fatal complication in this setting, although some reversible cases have been described in association with other liver transplantations. ${ }^{12}$ Liver transplantation for vanishing bile duct syndrome in Hodgkin's disease should be considered. Our patient died before any procedure could be done.

Table. Biochemical changes and chemotherapy in the Hodgkin's disease patient

\begin{tabular}{|c|c|c|c|c|c|c|c|c|}
\hline & Dec 97 & Feb 98 & Mar 98 & Apr 98 & May 98 & Jun 98 & Jul 98 & Normal \\
\hline Total bilirubin ( $\mu \mathrm{mol} / \mathrm{I})$ & 33.5 & 29.6 & 37.1 & 31.5 & 32 & 25.2 & 46 & $<1.2$ \\
\hline Direct bilirubin $(\mu \mathrm{mol} / \mathrm{l})$ & 22.7 & 20.6 & 24.5 & 20.5 & 22 & 16.3 & 24 & $<0.6$ \\
\hline AST (U/I) & 203 & 221 & 194 & 252 & 225 & 45 & 210 & $6-18$ \\
\hline A LT (U/I) & 203 & 319 & 170 & 219 & 130 & 41 & 84 & $4-22$ \\
\hline Alkaline Phosphatase (U/I) & 2041 & 1494 & 3566 & 5613 & 5804 & 2964 & 7970 & $65-200$ \\
\hline$\gamma-G T(U / I)$ & 809 & 1167 & 1972 & 2539 & 2085 & 1039 & 1860 & $4-23$ \\
\hline Albumin (g/dl) & 3.67 & - & - & 3.78 & 3.5 & 3.8 & 2.7 & $3.5-5.5$ \\
\hline PT (IN R) & 1.31 & 1.31 & 1.42 & - & 2.8 & 1.0 & 2.24 & 1.0 \\
\hline $\mathrm{R}$ & & & 0.83 & & & 1.33 & 5.41 & 1.0 \\
\hline Fibrinogen & 300 & & & & & & & $160-450$ \\
\hline Chemotherapy & MOPP/ ABV & MOPP/ ABV & MO PP/ ABV & MO PP/ ABV & HDCY & VP-16 & Death & - \\
\hline
\end{tabular}




\section{REFERENCES}

1. Jaffe ES. Malignant Lymphoma: Pathology of hepatic involvement. Semin Liver Dis 1987;7:257-68.

2. Hubscher SG, Lumley AL, Elias E. Vanishing bile duct syndrome: a possible mechanism for intrahepatic cholestasis in Hodgkin's Iymphoma. Hepatology 1993;17(1):70-7.

3. Gottrand F, Cullu F, Mazingue F, et al. Intrahepatic cholestasis related to vanishing bile duct syndrome in Hodgkin's disease. J Ped Gastroenterol Nutr 1997;24:430-3.

4. Desmet VJ. Vanishing bile duct disorders. Prog Liver Dis 1992;10:89-121.

5. Burra P, Elias E. Vanishing bile duct syndrome. Br J Surg 1992;79:604-5.

6. Galperin C, Gershwin ME. Immunopathogenesis of gastrointestinal and hepatobiliary diseases. JAMA 1997;278(22):1946-55.

7. Klimo P, Connors JM. MOPP/ABV hybrid program: combination chemotherapy based on early introduction of seven effective drugs for advanced Hodgkin's disease. J Clin Oncol 1985;3:1174-82.
8. Cervantes F, Briones J, Bruguera M, et al. Hodgkin's disease presenting as a cholestatic febrile illness: incidence and main characteristics in a series of 421 patients. Ann Hematol 1996;72:357-60.

9. Forbes GM, Jeffrey GP, Shilkin KB, Reed WD. Carbamazepine hepatotoxicity: another cause of the vanishing bile duct syndrome. Gastroenterology 1992;102:1385-8.

10. Altraif I, Lilly L, Wanless IR, Heathcote J. Cholestatic liver disease with ductopenia (vanishing bile duct syndrome) after administration of clindamycin and trimethoprim-sulphamethoxazole. Am J Gastroenterol 1994;89(8):1230-4.

11. Davies MH, Harrison RF, Elias E, Hubscher SG. Antibiotic-associated acute vanishing bile duct syndrome: a pattern associated with severe, prolonged, intrahepatic cholestasis. J Hepatol 1994;20(1):112-6.

12. Hubscher SG, Buckels JAC, Elias E, et al. Reversible Vanishing Bile Duct Syndrome after Liver Transplantation: Report of 6 Cases. Transplant Proc 1991;23(1):1415-6.

\section{resumo}

CONTEXTO: Lesões no fígado são relativamente comuns em pacientes com a Doença de Hodgkin. Uma pequena proporção dos casos desenvolvem icterícia. Recentemente, a síndrome do desaparecimento do duto biliar desenvolveu-se na Doença de Hodgkin. 0 s mecanismos dessa doença são muito pouco conhecidos até hoje.

OBJETVO: Descrever um raro caso de colestase relacionada à síndrome do desaparecimento dos dutos biliares.

TIPO DE ESTUDO: Relato de Caso.

RELATO DO CASO: Paciente masculino, 38 anos, portador de Doença de Hodgkin. A biópsia hepática revelou ausência de HD e colestase intra-hepática sendo que dos seis espaços porta analisados nenhum apresentava dutos biliares normais. 0 tratamento foi baseado em quimioterapia convencional e posterior quimioterapia em altas doses escalonadas. 0 paciente apresentou uma má evolução e faleceu devido a falência irreversível da função hepática, em remissão completa do linfoma.

PALAVRAS-CHAVE: Doença de Hodgkin. Síndrome do desaparecimento dos dutos biliares. Falência hepática.

\section{publishing information}

Marta Soares Rossini, MD. Hematology and Blood Transfusion Center, State University of Campinas, Campinas, Brazil.

Irene Lorand-Metze, MD. Department of Internal Medicine, State University of Campinas, Campinas, Brazil.

Gislaine Borba Oliveira, MD. Hematology and Blood Transfusion Center, State University of Campinas, Campinas, Brazil.

Cármino Antonio De Souza, MD. PhD. Department of Internal Medicine, State University of Campinas, Campinas, Brazil.

Sources of funding: Not declared Conflict of interest: Not declared

Last received: 11 August 1999

Accepted: 25 November 1999

Address for correspondence:

Cármino Antonio de Souza

Departamento de Medicina Interna, Faculdade de Ciências Médicas da

Universidade de Campinas

Cidade Universitária "Zeferino Vaz" - Caixa Postal 6198

Campinas/SP - Brasil - CEP 13081-970

e-mail: carmino@obelix.unicamp.br 